\title{
Explorations of wearable technology for tracking self and others
}

\author{
Sumin Helen $\mathrm{Koo}^{1 *}$ and Kristopher Fallon ${ }^{2}$
}

\author{
${ }^{*}$ Correspondence: \\ smkoo@konkuk.ac.kr \\ 1 Department of Apparel \\ Design, Konkuk University, \\ Seoul 05029, South Korea \\ Full list of author information \\ is available at the end of the \\ article
}

\begin{abstract}
The purpose of this research is to explore designs and functions people like to have in wearable trackers and how these differ between novice and experienced users. Interviews were conducted with 20 people, consisted of novice and experienced users living in the US, by asking preferred designs and functions of wearable trackers for oneself and others, preferences on sharing the tracked data, and suggestions in designs and functions of wearables. The data were analyzed qualitatively. It is recommended to make wearable trackers as accessory types that are small, lightweight, and neutral colored. Wearable trackers can offer self-tracking of moods and feelings for novice users and self-track physical activities for experienced users. Novice users are more likely to track others' physical health and experienced users preferred to track social media posts of others. Experienced users more reluctant to share their data with others than novice users. The results of this research will be helpful for designers, engineers, and marketers in the process of designing wearable technology.
\end{abstract}

Keywords: Product development, Wearable technology, Experience level, User

\section{Introduction}

The market for wearable technologies, wearable products and related technologies that incorporate fashion, computer sciences, advanced electronic technologies and other interdisciplinary areas, have significantly developed and a number of companies have released different types of wearables since 2014 (Büyüközkan et al. 2016; Page 2015). Among various wearable technologies, wearable trackers are one of the most common types. These are body-worn or hand-held devices or technologies that automatically collect data for better understanding of self, others, or the environment (Charara 2017; Lamkin 2015; Lupton 2014; Michaelis et al. 2016; Sawh 2017a; Schüll 2016). Examples of leading products with these functions include the Apple Watch, Samsung Gear, Fitbit, and Jawbone (Michaelis et al. 2016; Schüll 2016). Wearable trackers can enhance understanding of self, others, and the environment and enable users to select more appropriate reactions to new situations (Lupton 2014). Although there are many benefits, approximately $30 \%$ of individuals return their wearables after 6 months of use (Ledger and McCaffrey 2014; Michaelis et al. 2016).

To develop successful wearable trackers, it is essential to understand users of such trackers and their opinions on designs and functions by conducting interviews or analyzing comments as part of a user-centered design methodology (Holtzblatt et al. 2004;

(c) The Author(s) 2018. This article is distributed under the terms of the Creative Commons Attribution 4.0 International License (http://creativecommons.org/licenses/by/4.0/), which permits unrestricted use, distribution, and reproduction in any medium, provided you give appropriate credit to the original author(s) and the source, provide a link to the Creative Commons license, and indicate if changes were made. 
McCann 2009; Motti and Caine 2016). In previous research, significant differences were found between novice users (NC) and experienced users (EX) in their technology acceptance (Fishbein and Ajzen 1977), decision criteria (Bettman and Sujan 1987), perceived usefulness and periods of use (O'Cass and Fenech 2003; Smith and Brynjolfson 2001), purchase intentions (Sherrell et al. 2015), and use motivators (Stragier et al. 2016). Although, there is research on understanding user needs and wants for wearables (Gao et al. 2015; Koo and Fallon 2017; Koo et al. 2016; Stead et al. 2004), little attention has been paid to understanding the differences between NC and EX of wearable trackers. In addition, interviews are considered key techniques of user-centered design methodology, but there is a lack of research seeking to hear consumers' actual voices (Holtzblatt et al. 2004). Thus, the purpose of this research is to investigate what designs and functions NC and EX each like to have in wearable trackers and interviews were performed. The results of this research will be helpful for designers, engineers, and marketers in the process of designing wearable technology to target different level of EX.

\section{Literature review}

Literature reviews were conducted on (a) theoretical foundations to explore how different experience levels of users could influence user attitudes and behaviors; (b) the meanings of tracking oneself and others using wearables to understand how people would perceive tracking culture and what they would want from wearable trackers; and (c) the development and characteristics of wearable trackers to investigate what kinds of designs and functions of wearable trackers consumers have available in the market and which are missing. These literature reviews were used to prepare interview questions and to analyze the data for this study.

\section{Theoretical foundations}

The Unified Theory of Acceptance and Use of Technology (UTAUT) and Technology Acceptance Model (TAM) provide insights into experience level influences and facilitators and barriers to the use of wearables in this study. Two important factors for user acceptance of technology are perceived ease of use (PEOU) and perceived usefulness (PU) (Davis et al. 1989; Preusse et al. 2016; Ma et al. 2017; Venkatesh et al. 2012). Perusse et al's (2016) research found that lower PEOU and PU decreased the acceptance rate of wearables. Other problems and barriers to the use of wearable technology include weakness/lack of durability (Paul et al. 2014; Wang et al. 2016a, b), discomfort (Bowman et al. 2016), invasive monitoring (Coorevits and Coenen 2016), inaccuracy (Kim et al. 2007; Preusse et al. 2016); limited designs (Colgan et al. 2016; Tomberg et al. 2015; Wang et al. 2016a, b), cost (Donkin 2016), uselessness (Donkin 2016; Motti and Caine 2016) and difficulty of use (Coorevits and Coenen 2016). Researchers have endeavored to develop durable products that can withstand frequent washing or long-term use through methods such as coating the surface of the conductive materials or applying nanotechnologies (Paul et al. 2014; Wang et al. 2016a, b). According to the literature, consumers want wearable trackers to be useful, durable, comfortable, non-invasive, accurate, aesthetically pleasing, reasonably priced, useful, and easy to use and care for. The satisfaction with these aspects may affect consumer attitudes about wearable trackers. 
In previous research, researchers applied the TAM and found that user experience level affects the acceptance level of innovative technologies. The more experienced users are, the more likely they are to accept innovations (Fishbein and Ajzen 1977; Hsu et al. 2007; O'Cass and Fenech 2003). Experience level is also considered to be one of the major moderating factors in the UTAUT theory (Venkatesh et al. 2003). If users are more experienced, they have more familiarity with the technology and perceive the benefits of its use (Gerrard and Cunningham 2003). Also, EX tend to make more decisions when selecting products based on their memories than NC (Bettman and Sujan 1987). Stragier et al. (2016) studied new online fitness platforms, and NC were more driven by self-regulatory motives and social motives to use the new system, and enjoyment was more important for EX. Thus, the experience level may influence user preferences regarding designs and functions of wearable trackers.

\section{Tracking self and others}

Wearable technologies track blind spots and help users visualize everyday living in realtime (Schüll 2016; Swan 2013). Wearables can let individuals see and understand the reality of themselves and others, including choices they make such as taking the stairs or the elevator (Schüll 2016). Seeing these everyday choices allows individuals to see how their choices impact them and to enable or encourage them to make better choices (Schüll 2016). Wearable trackers can extend and improve self-awareness and self-management (Schüll 2016; Starner 2013). Schüll (2016) stated that wearables like personal sensors can be a sixth sense, capturing information which the ordinary senses cannot. Swan (2013) described these technologies as a sort of fourth-person perspective on the self. The self is considered the data in this era (Schüll 2016), however, other researchers, including anthropologists, have expressed concern about the growing use of these technologies. They argue that if the definition of the self is confined to a body that generates data, the ability to process experiencing and achieve self-understanding will atrophy. Since there are many aspects of the self and subjectivity that wearables still cannot track, the focus on data that can be tracked will increase the gap between the real self and the amassed, datafied self (Schüll 2016; Viseu and Suchman 2010).

Another use of self-tracking technology could be the self-adoption of government surveillance (Berson 2015). Miltgen et al. (2013) applied UTAUT and TAM to their research and found that concern for privacy influences the acceptance of tracking. Although wearables have tremendous potential to benefit people through functions such as managing individuals' health and providing insights to doctors (Bravo et al. 2016; Michaelis et al. 2016), many researchers have pointed out the privacy issues raised by tracking health data and users' activities through wearables (Brubaker 2017; Lamb et al. 2016; Li et al. 2016). With the development of big data analysis algorithms, information about health issues, activities, and location can be used by companies in fields, such as marketing, health insurance, medicine, social media, and more (Brubaker 2017). However, people may want to conceal their tracked data from others, and these tracked data can be hacked or sold by others without the users' knowledge. To solve privacy issues, wearables can limit the accessibility of users; develop security for networks to block hackers; and use biometrics such as fingerprints, pupils, walking patterns, and blood vessels; but more developments are required to solve the privacy issues created by the continuous 
evolution of wearable technologies (Blasco et al. 2016; Casale et al. 2012; Mitra and Wen 2016). Previous research has shown a relationship between personality and perceptions of the privacy of wearable technology. For example, people with a high tendency towards neuroticism knew more about third-party data sharing (Lamb et al. 2016). If individuals perceive more benefits than privacy risks, they may be more likely to adopt the device (Li et al. 2016). Thus, users may have different tendencies to share collected data with others according to data type and perceived privacy threat.

\section{Types of wearable trackers}

\section{Physical activities}

The most common type of wearables tracks physical activities. There are various types including smart watches, smart bands, patches, and garments. Wearable trackers for physical activities can quantify an individual's daily activity and have the benefit of being a cost-effective solution to motivate the individual to exercise (Michaelis et al. 2016). These wearables can track the user's location through a Global Positioning System (GPS); track vital signals such as heart rate (HR), burned calories, steps, speed, and time; monitor sport activities, sleep patterns, or even diet behaviors using accelerometers, gyroscopes, heart-rate sensors, galvanic skin response sensors; and can notify users when they achieve activity goals (Michaelis et al. 2016; Shelgikar et al. 2016). Smart watches are a representative type of fitness tracking wearables (Chittenden 2017). Smart watches can track multiple aspects of activities and have various other functions such as allowing users to manage calls and texts and set alarms to manage their schedule (Lamkin 2015; Sawh 2017a, b). Similar to smart watches, smart bands track multiple aspects of activity. However, smart bands are smaller and more simply designed than smart watches and have more limited screen interfaces (Charara 2017; Winchester 2015).

\section{Physical and psychological health}

Wearables can monitor specific disease symptoms through physical or psychological aspects and more (Chen et al. 2016; Davies 2017). The tracked data can be used for treatment, can provide information about users to medical professionals or families, or can be used as aids for daily life. Since people's behaviors are the biggest barriers to health (Schüll 2016), wearables can encourage users in health self-management, self-efficacy, and healthy habits (Preusse et al. 2016). Physical parameters such as HR, respirations, skin conductance level, and temperature can also be used to analyze users' psychological status including moods and feelings (Chen et al. 2016). For example, smart clothing is available to track moods and feelings in infants or people with mental disorder by tracking HR, respiration, or skin conductance (Singleton et al. 2014). For example, Zenta is a bracelet that can track feelings through physical signs such as HR (Fearn 2016).

\section{Environment and daily lifestyle}

Other types of wearables include devices that can track the weather or users' environment and wearables for schedule management. Scheduling wearables have functions such as notifying users when it is time to take medications, sending messages and calls, recording images or videos, and connecting to social networking media to transfer their tracked data such as information about health or location (Czaja 2016; Skolnik et al. 
2016). Such wearables can use GPS or RFID to automatically transfer data about users' locations to social networking media to indicate where the users are with families or friends (Su et al. 2016). Wearable camcorders have been developed to capture video; for example, Mark Schulze's mountain biking helmets, incorporated with compact video cameras, have been available since the 1980s. This type of product has been developed into devices such as GoPro, launched in 2004 (Winchester 2015). Since then, various kinds of wearable cameras have been introduced to the market, including cameras incorporated into clips or accessories such as glasses, watches, and necklaces (Lee et al. 2017; Nguyen 2016). Smart watches with schedule and task management tools are also available, but these overlap with smartphone functions. For example, the Apple watch alerts users to move or do other activities after a set amount of time, and Wunderlist, an app for the Apple watch, records to-do lists and reminds users of upcoming deadlines when tasks need to be finished (Fearn 2016).

In sum, based on the literature review, the following two research questions were derived: (1) what kind of designs and functions do NC and EX each want for wearable trackers? (2) what kind of designs and functions do NC and EX each like and dislike on existing wearable trackers?

\section{Methods}

\section{Population and study sample}

Interviews were conducted in this study to understand designs and functions people like to have in wearable trackers and their differences among people with different wearable trackers use experiences. After receiving approval from an Institutional Review Board (IRB), the researchers conducted personal interviews with participants. A total of 20 participants in the ages of 20-40 living in the US were recruited through purposeful sampling and were divided into two groups of ten participants each (Creswell 2013). This represent the major consumers of wearable technologies who are in the age range of 20s through 40s for both genders (Harris Poll 2015; Salah et al. 2014). The first participant group was consumers over the age of 18 who knew what wearable technology is but had no experience using wearables. The other group was EX over the age of 18 who knew what wearable technology is and had used wearables.

\section{Data collection procedure}

Emails were sent out through the university system and the local wearable technology community to recruit volunteers to participate in the interviews. Each participant was individually interviewed in person for about an hour in a university lab. Two interviewers explained the research purpose and procedures and received consent forms if participants agreed. The interviewers took notes and audiotaped the interviews.

\section{Interview questions}

The interview included nine questions: two about demographics such as age and gender, five about preferred tracking functions, and two about suggestions for wearable technology product designs. Five questions about tracking functions were used to answer research questions 1 and 2 on the designs and functions consumer wanted: (1) self-defining qualities: what qualities do you feel define who you are? (Schüll 2016); (2) tracking 
dimensions for self: 'what dimensions of yourself would you like to track?' (Koo and Fallon 2017; Preusse et al. 2016; Viseu and Suchman 2010); (3) knowing about others: what would you be interested to know about others? (Koo and Fallon 2017; Michaelis et al. 2016); (4) sharing about self: what qualities do you wish the world knew about you? (Koo and Fallon 2017; Lamb et al. 2016); (5) conceal about self: what qualities of yourself do you attempt to conceal? (Koo and Fallon 2017; Lamb et al. 2016; Li et al. 2016). The two questions about product design suggestions were asked: (1) what aspects do you like and dislike about current products? (Preusse et al. 2016) and (2) do you have any suggestions for improving the design and function of current wearable products in the market? (Michaelis et al. 2016; Preusse et al. 2016). Based on UTAUT and TAM, modifications and reinforcements could be made to wearable trackers that would enhance users' positive attitudes toward the devices based on the results. Such positive attitudes influence users' acceptance of new technologies (Wu et al. 2016).

Pilot interviews were conducted with four participants, two NC and two EX of wearables. Based on the pilot interview, the questions were modified to clarify the meanings by using easier words or adding more definitions of wearable technology related products, especially for NC. The definition of wearable technology for tracking was "devices that can collect data, track activities, and customize experiences to users' needs and desires" (Thierer 2015, p. 1). The examples of wearables were chosen to communicate with participants and to ask about their opinions of these wearables. The seven tracking wearables chosen were the Apple watch, Fitbit, Jawbone, Sensoria, Athos, Misfit, and Ringly. These products were selected based on three main criteria following Michaelis et al.s (2016) research method: (1) successful products which have recently become key players in the market (Michaelis et al. 2016); (2) products with a wide range of functionality such as accessories versus garments, and monitoring vital signs versus managing tasks and schedule; and (3) products which expert participants have used.

\section{Data analysis procedure}

The recorded files were transcribed for each question and open coded to extract important themes for qualitative data analysis (Creswell 2013; Tracy 2012). The numbers of common themes and participants were calculated for quantitative descriptive analysis such as frequency and percentage (Creswell 2013). The number of participants who mentioned each major theme was counted and divided by the total number of participants. There were participants who commented more than one major theme for each question. Tracking dimensions included fitness and physical health. Fitness can be analyzed by tracking physical activity and locations (Michaelis et al. 2016; Shelgikar et al. 2016). However, tracking health relies more on monitoring vital signs or symptoms of diseases (Chen et al. 2016; Davies 2017). Thus, in the data analysis, tracking disease symptoms was counted as tracking physical health and tracking general activities was counted as tracking fitness. Two researchers cross-checked the transcriptions and coded data and major themes. The total number of dividing agreements of the coded data was assessed using IBM's Statistical Package for the Social Sciences (SPSS) in version 23.0. The Cronbach's reliability coefficient was 0.908 , indicating good internal consistency (Shrout and Fleiss 1979). 


\section{Results and discussions}

\section{Sample characteristics}

The participants included ten NC of wearable technology [NC: mean $(\mathrm{M})_{\text {age }}=22$, standard deviation $(\mathrm{SD})_{\text {age }}=2.91$, range of 20-25, all females] and ten EX who had used wearables for at least a year $\left(\mathrm{EX}: \mathrm{M}_{\text {age }}=33.6, \mathrm{SD}_{\text {age }}=6.99\right.$, range of $26-40$, five females and five males). Among the EX, the most frequently used device was the Fitbit (60\%), followed by the Apple watch (30\%), Misfit (10\%), Athos (10\%), Sensoria (10\%), Jawbone (10\%), and Ringly (10\%).

\section{Research question 1 findings}

\section{Self-defining qualities}

When asked to define themselves, participants referred to their personality (35\%), physical activities (30\%), interpersonal relationship (20\%), physical attributes (10\%), and diet regulations (10\%) (Table 1). Among the NC, participants most commonly defined themselves by personality attributes (70\%) such as self-driven (50\%), extrovert (40\%), or creativeness $(40 \%)$ or introvert $(20 \%)$. The next most commonly mentioned attribute was physical activities (40\%) such as playing sports, active person, or being healthy, all of which are dimensions which many wearables track. Among the EX, participants most

Table 1 Results for the research question 1

\begin{tabular}{|c|c|c|c|c|c|}
\hline Category & Item & $\%$ & Sub-group & Item & $\%$ \\
\hline \multirow[t]{5}{*}{ Self-defining qualities } & Personality & 35 & NC & Personality & 70 \\
\hline & Physical activities & 30 & & Physical activities & 40 \\
\hline & Interpersonal relationship & 20 & & Physical attributes & 20 \\
\hline & Physical attributes & 10 & EX & Interpersonal relationships & 40 \\
\hline & Diet regulations & 10 & & Physical activities & 20 \\
\hline \multirow[t]{6}{*}{ Tracking dimensions for the self } & Physical activities & 60 & NC & Moods and feelings & 80 \\
\hline & Moods and feelings & 40 & & Physical activities & 80 \\
\hline & Diet regulations & 30 & & Diet regulations & 60 \\
\hline & Sleep patterns & 30 & & Sleep patterns & 60 \\
\hline & Consumption habits & 10 & EX & Physical activities & 40 \\
\hline & & & & Consumption habits & 20 \\
\hline \multirow[t]{4}{*}{ Knowing about others } & Physical health & 35 & NC & Physical health & 70 \\
\hline & Moods and feelings & 30 & & Moods and feelings & 60 \\
\hline & Locations & 15 & & Locations & 30 \\
\hline & Social media posts & 10 & EX & Social media posts & 20 \\
\hline \multirow[t]{6}{*}{ Sharing about self } & Moods and feelings & 20 & $\mathrm{NC}$ & Moods and feelings & 40 \\
\hline & Physical health & 15 & & Interests & 30 \\
\hline & Physical activities & 20 & & Physical health & 30 \\
\hline & Interests & 15 & EX & Not sharing & 50 \\
\hline & Not sharing & 25 & & Physical activities & 40 \\
\hline & Small groups & 15 & & Small groups & 30 \\
\hline \multirow[t]{4}{*}{ Conceal about self } & Personality & 40 & $\mathrm{NC}$ & Moods and feelings & 50 \\
\hline & Moods and feelings & 25 & & Personality & 30 \\
\hline & Physical attributes & 15 & & Physical attributes & 30 \\
\hline & & & EX & Personalities & 50 \\
\hline
\end{tabular}

NC novice users, EX experienced users 
commonly defined themselves by qualities such as interpersonal relationships (40\%) such as "maintenance of healthy and happy family and friend connections" (\#EX3). The next most common was physical activities (20\%). EX4 said, "I have always worked out," and EX9 commented, "I work out a lot...certainly staying fit and thin is something that I am very concerned about." Another common attribute was diet regulations (20\%). EX3 said, 'I think I am really aware about what I eat... I am really interested in eating healthy." Both NC and EX talked about physical activities, which are the most typical tracking dimensions of wearables (Mukhopadhyay 2015; Swan 2012). Physical activities were defined as the self-defining quality for both groups; however, $\mathrm{NC}$ cared more about personality and EX about interpersonal relationships. According to Lupton (2014), the tracking selfculture consists of self-awareness (understanding of self), self-improvement (adjusting the self), and self-interest (studying the self as an interesting subject). Tracking these attributes, that represent the self could help people visualize the self and allow people to be self-aware, self-improving, and self-interested (Schüll 2016; Swan 2013).

\section{Tracking dimensions for the self}

Among all participants, the dimension they most wanted to track in themselves was physical activities (60\%), followed by moods and feelings (40\%), diet regulations (30\%), sleep patterns (30\%), and consumption habits (10\%) (Table 1). NC and EX preferred somewhat different tracking dimensions for the self. NC wanted to track moods and feelings (80\%), such as anxiety or stress level, to enhance their self-awareness and selfregulation. For example, "Anxiety level...track when I'm most nervous and relaxed and can figure out why that is...stress levels" (\#NC1). "It would be cool to see my different stress levels at multiple points throughout the day and I could see if there are any peak points where my stress level is higher at a certain time" (\#NC3). "Distractions, nervousness, anxiety, tiredness, I think it's easier to deal with feeling nervous or anxious when I know it...if a watch or something were telling me I was nervous, I think I'd be less nervous..." (\#NC7). The other most preferred tracking dimension was physical activities (80\%), such as daily activities, exercises, and changes in the body like muscle gain, abdominal muscles, forearms, burning calories, bulking, heart rate, blood pressure, and dehydration levels. Participants wanted to track these activities to enhance their knowledge and growth. NC referred to eating habits as one of their self-defining qualities and also wanted to track diet regulations $(60 \%)$ through burned calories, weight loss, and diet. They also wanted to track sleep patterns $(60 \%)$ through their sleeping schedule and sleep quality. NC10 said, "...Tracking depth of sleep, how much sleep is best for health, what time I should wake up, and environmental factors affecting sleep."

EX also liked to track physical activities (40\%) such as running speed and duration and monitoring muscle changes while working out. The other dimension EX wanted to track was consumption habits (20\%) such as how much they spend in a year. These kinds of functions can be incorporated into apps for existing wearables instead of developing devices solely for tracking consumption habits. For example, the Billings Pro app for the Apple watch can track time, mileage, and expenses (Fearn 2016). Both NC and EX also considered physical activities to be important self-defining qualities, and many existing wearables track physical activities. Designers could develop wearable trackers that can track moods and feelings for NC and physical activities for both NC and EX. However, 
none discussed tracking their immediate surroundings and the environment in which they were located through practices such as recording photos or videos as reviewed in the literature.

\section{Knowing about others}

The most preferred aspects that NC were interested in knowing about others' physical health (70\%), which was also the most preferred when considering all participants. Tracking physical health included tracking heart rate or blood pressure. The other aspects the NC wanted to track in others were moods and feelings (60\%), including changes of moods and feelings or stress levels; and locations (30\%), such as using GPS and tracking children's locations for safety reasons. EX wanted to know about others' social media posts (20\%), including photos and writings people share on social media. Physical health, related to physical activities, and moods and feelings were also preferred tracking dimensions for the self. However, participants did not mention wanting to use location as an aspect of tracking the self. Developers would need to consider how to track these different data to satisfy different target groups of NC and EX.

\section{Sharing about self}

Participants in both groups wanted to share their moods and feelings (20\%), physical health (15\%), physical activities (20\%), and interests (15\%) (Table 1). However, 25\% of participants were reluctant to share tracked data or only wanted to share it with small groups (15\%). When asked what qualities they wanted other people to know about them, NC mentioned their psychological status such as moods and feelings (40\%), which others could use as a hint for better interpersonal relationships. Other information they wanted to share was their interests (30\%), to show "who I am and what I am good at," and physical health (30\%), such as burned calories and heart rate. Among EX, many preferred not sharing about themselves (50\%) due to discomfort and concerns about privacy. The aspects they wanted to share with others were physical activities (40\%) like number of steps they walked. Several wanted to share only with small groups $(30 \%)$ of their families or friends. Interestingly, none of the $\mathrm{NC}$ were concerned about the privacy issues that EX mentioned. Use experience could have raised these issues for EX (Drugge et al. 2006). Interestingly, $50 \%$ of EX, who have used wearables, did not want to share their tracked data with others, and only $30 \%$ wanted to share with small groups due to privacy issues, which was not commented by $\mathrm{NC}$. The experience of using wearables may arouse attention to privacy issues and developers could consider how to protect the privacy of users, and make them feel comfortable when using wearables (Drugge et al. 2006). Thus, designers would need to consider how to develop wearable trackers without violating privacy issues especially for EX.

\section{Conceal about self}

Participants in the NC wanted to conceal their moods and feelings (50\%) because they sometimes wanted to hide feelings such as anger, sadness, or nervousness (Table 1). They did not want to affect others or provide negative impressions. Another aspect they wanted to conceal was personality (30\%), such as lack of organization or lack of confidence, because they felt that these traits are private. Also, they wanted to hide physical 
attributes (30\%) like weight or skin imperfections. Similarly, EX also wanted to conceal personalities (50\%) such as negative personalities.

Participants wanted to conceal their moods and feelings, personalities, and physical attributes. However, personality was the most frequently mentioned self-defining quality and moods and feelings were one of the top desired functions for tracking the self, knowing about others, and sharing with others. People liked to know about others' moods and feelings but wanted to conceal their own. Information about individuals' personalities and moods and feelings could be used for tracking the self but not always shared with others. Thus, designers could consider how to better protect users' privacy while still providing the benefits of tracking. For example, data shared with others could use fewer specific words such as "stressed" when tracking moods and feelings (Raij et al. 2011). Designers of wearable technology might further consider the use of filters or permission dashboards to give users greater control over how their data is revealed to others and who gets to see it.

\section{Research question 2 findings}

The aspects that could affect consumer attitudes toward wearable trackers defined in the literature reviews and two main factors influencing acceptance of technologies in UTAUT and TAM were also found in the participants' responses (Table 2). Between the $\mathrm{NC}$ and EX groups, NC mentioned more design related aspects such as size and colors, and EX mentioned more functional aspects, and only EX mentioned privacy as a disliked aspect.

\section{Like and dislike aspects}

$\mathrm{NC}$ were those who had no experience in using wearable technology. Thus, they saw images and heard information about wearables such as Apple watch, Fitbit, Jawbone, Sensoria, Athos, Misfit, and Ringly, which were products that the EX group had used. When asked what aspects they liked about these products, NC mentioned small size $(40 \%)$ of wearables that made them more portable; unobtrusiveness $(40 \%)$ so that the wearables were invisible and could be used in various contexts; gender-neutral colors (30\%) such as black, beige, grey, or white; accessory type (20\%) so that the wearables could be used as fashionable items; the function of tracking mood and feelings (20\%) through methods such as measuring heart rate; simple designs $(20 \%)$ which made the products easy to use; and soft materials (20\%) so that the devices were comfortable to wear. EX liked functions of syncing to apps (40\%) such as automatically syncing the monitored data to apps and having an increased battery life (20\%) over previous versions or other wearables.

When asked what NC did not like, the aspect that participants mentioned most frequently was that wearables were unnecessary functions (40\%) because many of their functions overlapped with smartphone functions or the products required connecting with smartphones. The unnecessary functions, which relate to usefulness, could affect the acceptance of wearable trackers (Davis et al. 1989; Preusse et al. 2016; Venkatesh et al. 2012). Other disliked aspects were discomfort (30\%); color (20\%), such as bright or neon colors that are hard to match with various clothes and attract others' attention; and heavy weight (20\%). Also, cost (20\%) was mentioned as a barrier to using wearables. 
Table 2 Results for the research question 2

\begin{tabular}{|c|c|c|c|c|c|}
\hline Category & Aspect & $\%$ & Sub-group & Item & $\%$ \\
\hline \multirow[t]{9}{*}{ Liked aspects } & Small size (I) & 20 & NC & Small size (I) & 40 \\
\hline & Unobtrusiveness (I) & 20 & & Unobtrusiveness (I) & 40 \\
\hline & Syncing to apps (U, I, EU) & 20 & & Gender-neutral colors (A) & 30 \\
\hline & Gender-neutral colors (A) & 15 & & Accessory type $(A, U)$ & 20 \\
\hline & Accessory type $(A, U)$ & 10 & & Tracking mood and feelings $(U)$ & 20 \\
\hline & Tracking mood and feelings $(U)$ & 10 & & Simple designs (I, A, EU) & 20 \\
\hline & Simple designs (I, A, EU) & 10 & & Soft materials $(C, I)$ & 20 \\
\hline & Soft materials $(C, I)$ & 10 & EX & Syncing to apps (U, I, EU) & 40 \\
\hline & Battery life (U, EU, EC) & 10 & & Battery life $(\mathrm{U}, \mathrm{EU}, \mathrm{EC})$ & 20 \\
\hline \multirow{7}{*}{ Disliked aspects } & Unnecessary functions $(U)$ & 20 & NC & Unnecessary functions $(U)$ & 40 \\
\hline & Discomfort (D) & 15 & & Discomfort (D) & 30 \\
\hline & Color (A) & 10 & & Color (A) & 20 \\
\hline & Cost (P) & 10 & & Cost (P) & 20 \\
\hline & Durability (D) & 10 & EX & Durability (D) & 20 \\
\hline & Difficulty to use (EU) & 10 & & Difficulty to use (EU) & 20 \\
\hline & Privacy (R) & 10 & & Privacy (R) & 20 \\
\hline \multirow[t]{13}{*}{ Suggestions } & Fashionable (A) & 40 & NC & Fashionable (A) & 80 \\
\hline & Moods and feelings $(U)$ & 25 & & Unnoticeable (I) & 30 \\
\hline & $\begin{array}{l}\text { Schedule and task management } \\
\text { skills (U) }\end{array}$ & 20 & & Changeable $(U, A)$ & 30 \\
\hline & Physical health $(U)$ & 20 & & Lightweight (C, I) & 20 \\
\hline & Unnoticeable (I) & 15 & & Small $(C, I)$ & 20 \\
\hline & Changeable (U. A) & 15 & & Versatility in users $(U)$ & 20 \\
\hline & Lightweight (C, I) & 10 & & Moods and feelings $(U, A)$ & 20 \\
\hline & Small $(C, I)$ & 10 & & Cost $(P)$ & 20 \\
\hline & Versatility in users $(U, A)$ & 10 & EX & $\begin{array}{l}\text { Schedule and task management } \\
\text { skills }(U)\end{array}$ & 40 \\
\hline & Cost $(P)$ & 10 & & Physical health (U) & 40 \\
\hline & Physical attributes (U) & 10 & & Moods and feelings $(U)$ & 30 \\
\hline & Customizable $(\mathrm{U}, \mathrm{C}, \mathrm{A})$ & 10 & & Physical attributes (U) & 20 \\
\hline & & & & Customizable $(U, C, A)$ & 20 \\
\hline
\end{tabular}

$N C$ novice users, $E X$ experienced users, $U$ usefulness, $D$ durability, $C$ comfort, I invasiveness, $A$ aesthetically pleasing, $P$ price, $E U$ ease of use, $E C$ ease of care, $R$ perceived risk-privacy

Regarding the cost, consumers' perceived value of technology will enhance the acceptance of technologies (Donkin 2016; Preusse et al. 2016). The aspect EX disliked was durability (20\%) because using devices for daily activities can be limited when a device cannot be used in high temperatures, is not waterproof, or requires a great deal of maintenance. Participants also talked about the difficulty of use (20\%) such as setting up the device. Similarly, Preusse et al. (2016) also found that the disliked aspects of wearables included issues with difficulty of use. For example, "I realized that it would take me more than 5 min to set the thing up and sync it with my phone" (\#EX9). Some participants also worried about privacy (20\%), as EX3 mentioned:

I have looked at their policy and they have your data and they can do whatever they like with it. There are so many options like they are using your data for individual commercials and everything... I don't feel comfortable about sharing my data about anything. 


\section{Suggestions on designs and functions}

When participants were asked to suggest ways to improve the designs and functions of wearable products, $\mathrm{NC}$ wanted to improve the designs so that devices could be more fashionable (80\%) and not sporty, futuristic, high-tech, structured, or concrete looking; unnoticeable (30\%) so that they could be hidden or not stand out; changeable (30\%) so that the device could be personalized or matched with a variety of clothes in daily life; lightweight (20\%); small (20\%) so that the device could be more portable and worn for a long time; and suitable for versatility in users (20\%) such as elderly people to use. When asked about functions, they wanted to have accessories for tracking moods and feelings (20\%), such as nail polish, rings, or necklaces that can show when moods and feelings are changing dramatically or show the user's current mood. NC3 said, "Like with mood rings or mood necklaces in which the design/color could constantly change depending on the information it was receiving...it'd be cool to be able to tell from a glance that something is changing/updating." Participants also commended about wanting cost (20\%) to be more reasonable. Low cost can lower the risk level of accepting new technologies or products (Rogers 2003). EX suggested more focus on functions. Specifically, they wanted to enhance schedule and task management skills (40\%), managing physical health (40\%), and tracking moods and feelings (30\%). For example, "I think that it would be really cool if somehow, there was something that was like reading your mind or that like could be like, "Oh, you had this like emotional pattern, you know, and you tensed up here" (\#EX6). The other suggested functions are monitoring physical attributes (20\%) such as body size and weight, and being customizable (20\%), with features such as modifying codes or pressing buttons to change functions or interfaces.

\section{Conclusion and implication}

This research explored designs and functions people like to have for wearable trackers and how these are different between NC and EX. The results of this research will be beneficial for wearable technology developers and fashion designers in the development process. People in the fashion industry can market wearable trackers by considering possible designs and functions considering target groups of different experience levels.

Regarding to practical implications, it is recommended to make wearables as small, lightweight, neutral colored. Devices could be fashionable accessory types made of soft materials that automatically sync data to apps with increases battery lives. Designers can develop wearable trackers according to target users depend on their experience level of wearable technology. The functions could include: (1) self-tracking moods and feelings, physical activities, diet regulations, or sleep patterns for NC and physical activities or consumption habits for EX; and (2) tracking others on their physical health or moods and feelings for $\mathrm{NC}$ and social medial posts for EX. These functions were recommended to be independent from smartphones, thus, the wearables are necessary in themselves. Since EX more concerned about the privacy issue, designers would need to consider how to protect tracked data when targeting EX.

Wearables could also be useful, non-invasive, aesthetically pleasing, easy to use, comfortable, durable, reasonably priced, easy to care for, and capable of protecting the privacy of users. Many researchers found that user experience level affect the acceptance 
level (Fishbein and Ajzen 1977; Hsu et al. 2007; O'Cass and Fenech 2003; Venkatesh et al. 2003). Thus, it would be worthwhile for designers to consider different preferences and attitudes towards wearable trackers between NC and EX and this may influence the acceptance rate according to the UTAUT and TAM. The designs and functions could also be changeable for personalization or for use in various contexts. Increased ease of use may also increase the acceptance rate of the wearables based on the UTAUT and TAM, and ease of use could be enhanced by making an effort to understand the users and use context, providing tutorial videos, providing navigation and accuracy hints, or providing trial-use periods (Davis et al. 1989; Preusse et al. 2016; Venkatesh et al. 2012).

The privacy protection could also be important on wearables especially when tracking moods and feelings, personalities, physical attributes, and physical health (Brubaker 2017; Lamb et al. 2016; Li et al. 2016). Thus, developers would need to consider how to protect users' privacy such as providing options on the wearables of sharing the tracked data with others or even with the companies; to limit the accessibility of users; to develop security against hackers; or to use biometrics as reviewed in the literature (Blasco et al. 2016; Casale et al. 2012; Mitra and Wen 2016).

This study only interviewed with 20 people in the US with uneven portion of male and female participants in a wide range of ages focusing on wearables for tracking functions. It will be worthwhile to conduct quantitative surveys or user tests with existing wearables with participants with different demographic backgrounds including age, gender, resident location, and occupations such as developers on wearables for tracking or with different functions as future research. In addition, the future study of the modeling testing with UTAUT and TAM using the quantitative study design would be meaningful.

Authors' contributions

SK conducted interviews, analyze data, and wrote the manuscript. KF conducted interviews and contributed to the manuscript writing. All authors read and approved the final manuscript.

Author details

${ }^{1}$ Department of Apparel Design, Konkuk University, Seoul 05029, South Korea. ${ }^{2}$ University of California, Davis, Davis, CA 95616, USA.

Acknowledgements

This paper was supported by Konkuk University in 2017.

Consent for publication

Not applicable.

Ethical approval and consent to participate

Written informed consent was obtained from all participants for the research.

Competing interests

The authors declare that they have no competing interests.

Publisher's Note

Springer Nature remains neutral with regard to jurisdictional claims in published maps and institutional affiliations.

Received: 12 February 2017 Accepted: 20 September 2017

Published online: 28 March 2018

\section{References}

Berson, J. (2015). Computable bodies: Instrumented life and the human somatic niche. London: Bloomsbury.

Bettman, J. R., \& Sujan, M. (1987). Effects of framing on evaluation of comparable and noncomparable alternatives by expert and novice consumers. Journal of Consumer Research, 14(2), 141-154.

Blasco, J., Chen, T. M., Tapiador, J., \& Peris-Lopez, P. (2016). A survey of wearable biometric recognition systems. ACM Computing Surveys, 49(3), 43 
Bowman, N., Banks, J., \& Westerman, D. (2016). Through the looking glass (self): The impact of wearable technology on perceptions of face-to-face interaction. Communication Research Reports, 33(4), 332-340.

Bravo, D., Swensen, S., \& Lajam, C. (2016). Fitness tracking devices: Applications in orthopedics. Bone and Joint Journal, 98(7), 50.

Brubaker, H. (2017). Wearable tech gaining in health care, but privacy is a concern. Philly. http://www.philly.com/philly/ business/Wearable-tech-gaining-in-health-care-butwhat-about-privacy.html. Retrieved 21 Jan 2017.

Büyüközkan, G., Güler, M., \& Uztürk, D. (2016). Selection of wearable glasses in the logistics sector. In Proceedings from the 14th international logistics and supply chain congress (pp. 377).

Casale, P., Pujol, O., \& Radeva, P. (2012). Personalization and user verification in wearable systems using biometric walking patterns. Personal and Ubiquitous Computing, 16(5), 563-580.

Charara, S. (2017). The best wearable tech at CES 2017. Wearable. Retrieved January 12, 2017, from https://www.wareable. $\mathrm{com} /$ ces/ces-2017-new-wearable-tech.

Chen, M., Ma, Y., Song, J., Lai, C. F., \& Hu, B. (2016). Smart clothing: Connecting human with clouds and big data for sustainable health monitoring. Mobile Networks and Applications, 21(5), 825-845.

Chittenden, T. (2017). Skin in the game: The use of sensing smart fabrics in tennis costume as a means of analyzing performance. Fashion and Textiles, 4(22), 1-21.

Colgan, J. C., Bopp, M. J., Starkoff, B. E., \& Lieberman, L. J. (2016). Fitness wearables and youths with visual impairments: Implications for practice and application. Journal of Visual Impairment \& Blindness, 110(5), 335.

Coorevits, L., \& Coenen, T. (2016). The rise and fall of wearable fitness trackers. Academy of Management. Retrieved January 7, 2016, from https://biblio.ugent.be/publication//file/8056002.pdf.

Creswell, J. W. (2013). Research design: Qualitative, quantitative, and mixed methods approaches. Thousand Oaks, CA: Sage publications.

Czaja, S. J. (2016). Long-term care services and support systems for older adults: The role of technology. American Psychologist, 71(4), 294.

Davies, W. (2017). How are we now? Real-time mood-monitoring as valuation. Journal of Cultural Economy, 10(1), 34-48.

Davis, F. D., Bagozzi, R. P., \& Warshaw, P. R. (1989). User acceptance of computer technology: A comparison of two theoretical models. Management Science, 35(8), 982-1003.

Donkin, C. (2016). Wearables seen as useless and expensive. Mobile World Live. Retrieved January 10, 2016 from https:// www.mobileworldlive.com/devices/news-devices/wearables-seen-as-useless-and-expensive-gartner/.

Drugge, M., Hallberg, J., Parnes, P., \& Synnes, K. (2006). Wearable systems in nursing home care: Prototyping experience. IEEE Pervasive Computing, 5(1), 86-91.

Fearn, N. (2016). 8 tips for being more productive with wearable tech. Wearable. Retrieved November 21, 2016, from https ://www.wareable.com/wearable-tech/tips-productivity-wearables-apps-445.

Fishbein, M., \& Aizen, I. (1977). Belief, attitude, intention, and behavior: An introduction to theory and research. Journal of Business Venturing, 5, 177-189.

Gao, Y., Li, H., \& Luo, Y. (2015). An empirical study of wearable technology acceptance in healthcare. Industrial Management and Data Systems, 115(9), 1704-1723.

Gerrard, P., \& Cunningham, J. (2003). The diffusion of internet banking among Singapore consumers. International Journal of Bank Marketing, 21(1), 16-28.

Harris Poll. (2015). Wearable tech familiarity and consideration on the rise. The Harris Poll. Retrieved January, 20, 2016, from http://www.theharrispoll.com/business/Wearable-Tech.html.

Holtzblatt, K., Wendell, J. B., \& Wood, S. (2004). Rapid contextual design: A how-to guide to key techniques for user-centered design. Kidlington: Elsevier.

Hsu, M. H., Ju, T. L., Yen, C. H., \& Chang, C. M. (2007). Knowledge sharing behavior in virtual communities: The relationship between trust, self-efficacy, and outcome expectations. International Journal of Human Computer Studies, 65(2), 153-169.

Kim, H. W., Chan, H. C., \& Gupta, S. (2007). Value-based adoption of mobile internet: an empirical investigation. Decision support systems, 43(1), 111-126.

Koo, H. S., \& Fallon, K. (2017). Preferences in tracking dimensions for wearable technology. International Journal of Clothing Science and Technology, 29(2), 180-199.

Koo, H. S., Michaelson, D., Teel, K., Kim, D. J., Park, H., \& Park, M. (2016). Design preferences on wearable e-nose systems for diabetes. International Journal of Clothing Science and Technology, 28(2), 216-232.

Lamb, K., Huang, H. Y., Marturano, A., \& Bashir, M. (2016). Users' privacy perceptions about wearable technology: Examining influence of personality, trust, and usability. In D. Nicholson (Ed.), Advances in human factors in cybersecurity (pp. 55-68). New York, NY: Springer International Publishing.

Lamkin, P. (2015). Smartwatch timeline: The devices that paved the way for the Apple Watch. Retrieved July 23, 2016, from https://www.wareable.com/smartwatches/smartwatch-timeline-history-watches.

Ledger, D., \& McCaffrey, D. (2014). Inside wearables. How the science of human behavior change offers the secret to long-term engagement. Retrieved August 15, 2016, from http://endeavourpartners.net/assets/En-deavour-Partn ers-Wearables-and-the-Science-of-Human-Behavior-Change-Part-1-January-20141.pdf.

Lee, C. K., Kim, Y., Lee, N., Kim, B., Kim, D., \& Yi, S. (2017). Feasibility study of utilization of action camera, GoPro Hero 4, Google Glass and Panasonic HX-A100 in spine surgery. Spine, 42(4), 275-280.

Li, H., Wu, J., Gao, Y., \& Shi, Y. (2016). Examining individuals' adoption of healthcare wearable devices: An empirical study from privacy calculus perspective. International Journal of Medical Informatics, 88, 8-17.

Lupton, D. (2014). Self-tracking cultures: towards a sociology of personal informatics. In Proceedings from the Australian computer-human interaction conference on designing futures: The future of design (pp. 77-86). New York, NY: ACM.

Ma, Y. J., Gam, H. J., \& Banning, J. (2017). Perceived ease of use and usefulness of sustainability labels on apparel products: application of the technology acceptance model. Fashion and Textiles, 4(3), 1-20.

McCann, J. (2009). End-user based design of innovative smart clothing. In J. McCann \& D. Bryson (Eds.), Smart clothes and wearable technology (pp. 45-69). Kidlington: Elsevier. 
Michaelis, J. R., Rupp, M. A., Kozachuk, J., Ho, B., Zapata-Ocampo, D., McConnell, D. S., \& Smither, J. A. (2016). Describing the user experience of wearable fitness technology through online product reviews. In Proceedings from the human factors and ergonomics society annual meeting (Vol. 60, No. 1, pp. 1073-1077). Los Angeles, CA: SAGE Publications.

Miltgen, C. L., Popovič, A., \& Oliveira, T. (2013). Determinants of end-user acceptance of biometrics: Integrating the "Big 3" of technology acceptance with privacy context. Decision Support Systems, 56(2013), 103-114.

Mitra, S., \& Wen, B. (2016). Current and future trends in biometrics. In M. Sinjini \& M. Gofman (Eds.), Biometrics in a data driven world: Trends, technologies, and challenges (pp. 345-384). Boca Raton, FL: CRC Press.

Motti, V. G., \& Caine, K. (2016). Smart wearables or dumb wearables?: Understanding how context impacts the UX in wrist worn interaction. In Proceedings from the 34th ACM international conference on the design of communication (Vol. 10). New York, NY: ACM.

Mukhopadhyay, S. C. (2015). Wearable sensors for human activity monitoring: A review. IEEE Sensors Journal, 15(3), $1321-1330$.

Nguyen, M. (2016). The best wearable camera for you. Wearable Technologies. Retrieved August 10, 2016 from https:// www.wearable-technologies.com/2016/03/the-best-wearable-camera-for-you/.

O'Cass, A., \& Fenech, T. (2003). Web retailing adopction: Exploring the nature of internet users web retailing behavior. Journal of Retailing and Consumer Services, 10(2003), 81-94.

Page, T. (2015). A forecast of the adoption of wearable technology. International Journal of Technology Diffusion, 6(2), $12-29 . d$

Paul, G., Torah, R., Yang, K., Beeby, S., \& Tudor, J. (2014). An investigation into the durability of screen-printed conductive tracks on textiles. Measurement Science \& Technology, 25(2), 1-11.

Preusse, K. C., Mitzner, T. L., Fausset, C. B., \& Rogers, W. A. (2016). Older adults' acceptance of activity trackers. Journal of Applied Gerontology, 36(2), 127-155.

Raij, A., Ghosh, A., Kumar, S., \& Srivastava, M. (2011). Privacy risks emerging from the adoption of innocuous wearable sensors in the mobile environment. In Proceedings of the conference on human factors in computing systems (pp 11-20). New York, NY: ACM.

Rogers, E. M. (2003). Diffusion of innovations. New York, NY: Free Press.

Salah, H., Maclntosh, E., \& Rajakulendran, N. (2014). Wearable tech: Leveraging Canadian innovation to improve health. Mars Library. Retrieved January 21, 2016, from http://www.marsdd.com/mars-library/wearable-tech-leveraging -canadian-innovation-to-improve-health.

Sawh, M. (2017a). Garmin Fenix 5 first look: King of the outdoor watches just got even better. Wearable. Retrieved January 10, 2017, from https://www.wareable.com/garmin/garmin-fenix-5-review.

Sawh, M. (2017b). New balance RunlQ first look: Android wear made for runners. Wearable. Retrieved January 10, 2017, from https://www.wareable.com/smartwatches/new-balance-runiq-review.

Schüll, N. D. (2016). Data for life: Wearable technology and the design of self-care. BioSocieties, 11(3), 317-333.

Shelgikar, A. V., Anderson, P. F., \& Stephens, M. R. (2016). Sleep tracking, wearable technology, and opportunities for research and clinical care. Chest Journal, 150(3), 732-743.

Sherrell, D. L., Biswas, A., \& Alford, B. L. (2015). The influence of prior product and store knowledge on consumer reference price estimates. In Proceedings of the 1991 Academy of Marketing Science (AMS) Annual Conference (pp 12-16). Cham: Springer.

Shrout, P. E., \& Fleiss, J. L. (1979). Intraclass correlations: Uses in assessing rater reliability. Psychological Bulletin, 86(2), 420.

Singleton, G., Warren, S., \& Piersel, W. (2014). Clinical overview of the need for technologies for around-the-clock monitoring of the health status of severely disabled autistic children. In Proceedings from the engineering in medicine and biology society (pp. 789-791). New York, NY: IEEE.

Skolnik, A. B., Chai, P. R., Dameff, C., Gerkin, R., Monas, J., Padilla-Jones, A., et al. (2016). Teletoxicology: Patient assessment using wearable audiovisual streaming technology. Journal of Medical Toxicology, 12(4), 358-364.

Smith, M., \& Brynjolfson, E. (2001). Consumer decision making at an internet shopbot: Brand still matters. The Journal of Industrial Economics, 49(4), 541-558.

Starner, T. (2013). Project glass: An extension of the self. IEEE Pervasive Computing, 12(2), 14-16.

Stead, L., Goulev, P., Evans, C., \& Mamdani, E. (2004). The emotional wardrobe. Personal and Ubiquitous Computing, 8(3-4), 282-290.

Stragier, J., Abeele, M. V., Mechant, P., \& De Marez, L. (2016). Understanding persistence in the use of online fitness communities: Comparing novice and experienced users. Computers in Human Behavior, 64(2016), 34-42.

Su, Z., Xu, Q., Zhang, K., \& Shen, X. S. (2016). Modeling and optimization for mobile social networks. New York, NY: Springer International Publishing.

Swan, M. (2012). Sensor mania! the internet of things, wearable computing, objective metrics, and the quantified self 2.0 . Journal of Sensor and Actuator Networks, 1(3), 217-253.

Swan, M. (2013). The quantified self: Fundamental disruption in big data science and biological discovery. Big Data, 1(2), $85-99$.

Thierer, A. D. (2015). The internet of things and wearable technology: Addressing privacy and security concerns without derailing innovation. Richmond Journal of Law and Technology, 21(2), 1-118.

Tomberg, V., Schulz, T., \& Kelle, S. (2015). Applying universal design principles to themes for wearables. In Proceedings from the international conference on universal access in human-computer interaction (Vol. 9176, pp. 550-560). New York, NY: Springer International Publishing.

Tracy, S. J. (2012). Qualitative research methods: Collecting evidence, crafting analysis, communicating impact. San Francisco, CA: Wiley.

Venkatesh, V., Morris, M. G., Davis, G. B., \& Davis, F. D. (2003). User acceptance of information technology: Toward a unified view. MIS Quarterly, 27(3), 425-478.

Venkatesh, V., Thong, J. Y., \& Xu, X. (2012). Consumer acceptance and use of information technology: extending the unified theory of acceptance and use of technology. MIS Quarterly, 36(1), 157-178.

Viseu, A., \& Suchman, L. (2010). Wearable augmentations: Imaginaries of the informed body. In J. Edwards, P. Harvey, \& P. Wade (Eds.), Technologized images, technologized bodies (pp. 161-184). New York: Berghahn Books. 
Wang, Y., Gong, S., Wang, S. J., Simon, G. P., \& Cheng, W. (2016a). Volume-invariant ionic liquid microbands as highly durable wearable biomedical sensors. Materials Horizons, 3(3), 208-213.

Wang, J., Juhlin, O., Blomgren, E., Bågander, L., Kägo, E., Meier, F., Takahashi, M, \& Thornquist, C. (2016b). Design space of the new materials for fashionable wearables. In Proceedings from the 18th international conference on human-computer interaction with mobile devices and services adjunct (pp. 1159-1162). New York, NY: ACM.

Winchester, H. (2015). A brief history of wearable tech. Wearable. Retrieved January 2, 2017, from https://www.wareable. com/wearable-tech/a-brief-history-of-wearables.

Wu, L. H., Wu, L. C., \& Chang, S. C. (2016). Exploring consumers' intention to accept smartwatch. Computers in Human Behavior, 64(2016), 383-392.

Submit your manuscript to a SpringerOpen ${ }^{\circ}$ journal and benefit from:

- Convenient online submission

Rigorous peer review

- Open access: articles freely available online

- High visibility within the field

Retaining the copyright to your article

Submit your next manuscript at $\mathbf{s p r i n g e r o p e n . c o m ~}$ 